\title{
Patient Perspectives on Nurse-led Consultations Within a Pilot Structured Transition Program for Young Adults Moving From an Academic Tertiary Setting to Community-based Type 1 Diabetes Care
}

\author{
Sandra Zoni ${ }^{\text {a,1 }}$, Marie-Elise Vergd ${ }^{b, 1}$, Michael Hauschild ${ }^{\mathrm{c}}$, Marie-Paule Aquarone-Vaucher ${ }^{\mathrm{c}}$, Teresa Gyuriga ${ }^{\mathrm{c}}$, \\ Anne-Sylvie Ramelet ${ }^{\mathrm{a}, \mathrm{d}, 2}$, Andrew A. Dwyer ${ }^{\mathrm{a}, \mathrm{e}, *, 2}$ \\ a University of Lausanne Institute of Higher Education and Research in Healthcare, Lausanne, Switzerland \\ ${ }^{\mathrm{b}}$ Haute école de santé Fribourg, Fribourg Switzerland \\ c Centre Hospitalier Universitaire Vaudois (CHUV) Pediatric Endocrinology, Diabetes and Metabolism Service of the Department of Maternal and Child Health, Lausanne, Switzerland \\ d Centre Hospitalier Universitaire Vaudois (CHUV) Department of Maternal and Child Health, Lausanne, Switzerland \\ e Centre Hospitalier Universitaire Vaudois (CHUV) Endocrinology, Diabetes and Metabolism Service, Lausanne, Switzerland
}

\section{A R T I C L E I N F O}

\section{Article history:}

Received 10 June 2017

Revised 27 November 2017

Accepted 28 November 2017

\section{Keywords:}

Adolescent health services

Nursing

Transition

Type 1 diabetes mellitus

\begin{abstract}
A B S T R A C T
Purpose: We aimed to evaluate patient self-management activities, patient perceptions of the therapeutic relationship and satisfaction with nurse-led consultations as part of a structured, pilot program transitioning young adults with type 1 diabetes (T1DM) to adult-oriented community-based practices.

Design and Methods: A descriptive, cross-sectional study of patients receiving nurse-led consultations. Patients provided sociodemographic/health information, glycated hemoglobin (HbA1c) measures and completed questionnaires assessing self-management (Revised Self-Care Inventory) and the therapeutic relationship (Caring Nurse-Patient Interaction - short scale). HbA1c values were compared to guideline recommendations. Results: Twenty patients participated. HbA1c was $\leq 7.5 \%$ in $3 / 14(21 \%)$ and $5 / 14$ (36\%) exhibited poor glycemic control $(\geq 9.5 \%)$. The greatest concordance for self-care was in relation to insulin therapy $(4.5 \pm 0.5)$ while patients reported the lowest adherence to diet recommendations $(2.9 \pm 0.8)$. Overall satisfaction with nurse-led consultations was high ( $4 \pm 0.5$ out of 5 ). Patients considered diabetes knowledge and technical competence as very important and were most pleased with the humanistic aspects of nursing care. Respect for privacy was deemed the most important (and most frequently observed) nursing attitude/behavior during consultations. Conclusions: Young adults found the nurse-led consultations with therapeutic education to develop T1DM selfcare skills are an important complement to medical management during transition.

Practice Implications: Patient autonomy and privacy should be respected during this developmental period. Nurses taking a humanistic approach towards accompanying and supporting the patient can enhance the therapeutic relationship during transition and promote continuity of care. Transition nurses can use technical competence and therapeutic education to empower patients for self-management.
\end{abstract}

@ 2017 Elsevier Inc. All rights reserved.

\section{Introduction}

Type 1 diabetes mellitus (T1DM) is thought to result from immunemediated destruction of pancreatic beta cells that produce insulin. Patients with T1DM have increased morbidity and mortality resulting from micro- and macro-vascular sequelae secondary to glycemic

\footnotetext{
* Corresponding author at: Andrew A. Dwyer.

E-mail address: andrew.dwyer@bc.edu (A.A. Dwyer).

1 Equal lead author contribution.

2 Equal senior authors contribution.
}

variations including hypo- and hyperglycemia (Rawshani et al., 2017). While the precise genetic, environmental and behavioral factors underlying T1DM remain to be fully elucidated (Peng \& Hagopian, 2006), it is clear that patients require lifelong insulin therapy. As demonstrated in two large trials, the Diabetes Control and Complications Trial (DCCT) and the Epidemiology of Diabetes Interventions and Complications (EDIC) (Dunger, 2017; Lachin, Orchard, Nathan, and DCCT/EDIC Research Group, 2014), management focuses on tight glycemic control to minimize both short- and long-term complications. T1DM is primarily diagnosed in young children and adolescents with the peak incidence observed between 10 and 14 years of age (Maahs, West, Lawrence, \& Mayer-Davis, 2010). Notably, recent data suggest the incidence and prevalence of T1DM in children and adolescents $<16$ years 
appears to be rising by approximately $1.4 \%$ annually (Mayer et al., 2017).

For patients with T1DM, adolescence can be a challenging period due to complex treatment requirements, the physical and hormonal changes of pubertal onset, as well as the psychological and social changes during this time of development (Hauschild et al., 2015). Unfortunately, this confluence of issues often results in deteriorating glycemic control. International data have identified significant shortfalls as only about $14 \%$ patients with T1DM aged 11-18 years actually achieve glycated hemoglobin (HbA1c) levels of $<7.5 \%$ (Dunger, 2017; Maahs et al., 2014; Miller et al., 2015) which is the consensus target identified by the American Diabetes Association (ADA) and the International Society for Pediatric and Adolescent Diabetes (ISPAD) (American Diabetes, 2016; Rewers et al., 2014).

Transition is often associated with being lost to follow-up and adverse health outcomes (Garvey, Markowitz, \& Laffel, 2012; Lotstein et al., 2013; Lyons, Becker, \& Helgeson, 2014). For young adults with T1DM continuity of care is critical for minimizing acute and long-term complications. Transfer can be challenging for young adults as evidence suggests that at least four to five visits are needed to establish a trusting relationship with a new medical provider (Klostermann, Slap, Nebrig, Tivorsak, \& Britto, 2005). Yet when continuity of care is actively promoted, acute complications and hospitalizations can be dramatically decreased (Nakhla, Daneman, To, Paradis, \& Guttmann, 2009).

Because patients receive initial care in a pediatric setting, effective programs are needed to transition patients to adult-oriented care settings. Prior studies have employed a range of approaches to care coordination and transition planning to navigate the passage to adult-oriented care (Garvey et al., 2012). Some have provided administrative support to arrange appointments and send reminders (Holmes-Walker, Llewellyn, \& Farrell, 2007). The Maestro project utilized an administrative project coordinator for continued telephone and e-mail contact to identify barriers to access and help support the navigation process (Van Walleghem, Macdonald, \& Dean, 2008). Others have used a transition coordinator to provide anticipatory guidance and information about transition ahead of a joint pediatrician-adult endocrinologist consultation and hand-off of care (Cadario et al., 2009).

Transitional care for young adults with special healthcare needs has gained increasing attention and has been the topic of several systematic reviews (Betz, O'Kane, Nehring, \& Lobo, 2016; Campbell et al., 2016) and a recent position statement from the Society of Pediatric Nurses (Betz, 2017). For patients with diabetes, who provide $>95 \%$ of their own care (Funnell \& Anderson, 2000), developing self-management skills is a critical part of the transition process. Psychological support and therapeutic education are key elements of developing self-care skills and can help foster independence and autonomy during transition to adult-oriented community-based practices. However, it remains unclear how this is best achieved. Moreover, patient perspectives are not always considered when examining such transitional care programs (Betz, Lobo, Nehring, \& Bui, 2013).

To enhance care for young adults with T1DM in the canton (state/ province) of Vaud Switzerland, a structured transition program was developed to ease the transfer of patient care for young adults with T1DM from the regional tertiary academic children's hospital to adult-oriented community-based practices. This program utilized nurse-led consultations to coach and guide patients during this process. We examined patient perspectives on this transitional care model.

\section{Methods}

Broadly, this cross-sectional descriptive study intended to evaluate patient self-management activities, patient perceptions of the therapeutic relationship and satisfaction with nurse-led consultations as part of a structured, pilot program transitioning young adults with type 1 diabetes (T1DM) to adult-oriented community-based practices. To do this, we evaluated patient outcomes including: glycated hemoglobin levels
(HbA1c), self-care activities as well as patient perceptions of and satisfaction with caring attitudes and behaviors (i.e. therapeutic relationship). To conceptualize the complex patient-caregiver dynamic during transition, we used the Interaction Model of Client Health Behavior as a guiding theoretical framework (Cox, 1982).This model recognizes the contribution of individual characteristics (e.g. demographics, past experiences and resources) and states that cognitive and affective aspects of patient-provider interactions mediate outcomes. To examine the nurse-led consultations, we started with the notion that a sound therapeutic relationship is critical for effective patient education and psychological support of young adults during transition. The study was reviewed and approved by the local human research ethics committee (Commission cantonale d'éthique de la recherche sur l'être humain).

\section{Nurse-led Transition Consultation}

In Switzerland, as in many countries, patients with T1DM are primarily diagnosed (and initially treated) at a regional, tertiary academic medical center. For many patients, this requires significant travel for ongoing care and many eventually seek community-based care at a local physician's office to make ongoing management more convenient. In 2012, the Pediatric Endocrinology, Diabetes and Metabolism Service of the University Hospital of Lausanne developed a pilot structured transition project to transfer care to community-based practices while promoting self-management and continuity of care. To complement the care from the medical team, a dedicated transition nurse provided individualized coaching and therapeutic education during transition and served a navigator role to ensure that patients attended initial visits to adult-oriented community-based practices and were psychologically supported through the transition process. This complex nursing intervention included aspects in the pediatric care setting that bridged to adult-oriented community-based practices (Fig. 1).

More specifically, the transition nurse is introduced to the patient in the pediatric setting and begins ongoing discussions to assess readiness for transition, preferred setting (i.e. adult academic medical center vs. adult-oriented community-based practice) as well as self-care needs and anticipatory guidance. The nurse reinforces key diabetes self-care aspects with particular attention to autonomy (i.e. managing supplies and prescriptions, keeping and making appointments). Based on patient preference, the transition nurse is available via home visits, telephone, email or text messaging (SMS) facilitating continued interaction ranging in frequency from weekly to every three to six months based on individual patient needs. This provides a safe, known individual for supporting the transition process. Nursing interventions include active listening support, motivational interviewing, therapeutic education, observing the practice of day-to-day self-care techniques (and providing feedback), helping with administrative concerns as well as accompanying patients to the first contact with the adult provider and ensuring subsequent visits. Care is individualized and may comprise brief text messages or extended hour-long home visits.

\section{Participants and Recruitment}

Fifty eight young adults with T1DM between the ages of 16 and 25 years who had received at least two consultations were invited to participate. Participants 18 years and older provided written informed consent while minors gave assent in addition to parental consent. Participants provided sociodemographic information and completed questionnaires (paper or web-based). To gain insight into glycemic control over the prior 90 days, participants were asked for permission to contact their provider to obtain the most recent HbA1c level ( \pm 2 months from date of questionnaire completion) Recruitment lasted four months (November 2015-February2016). 


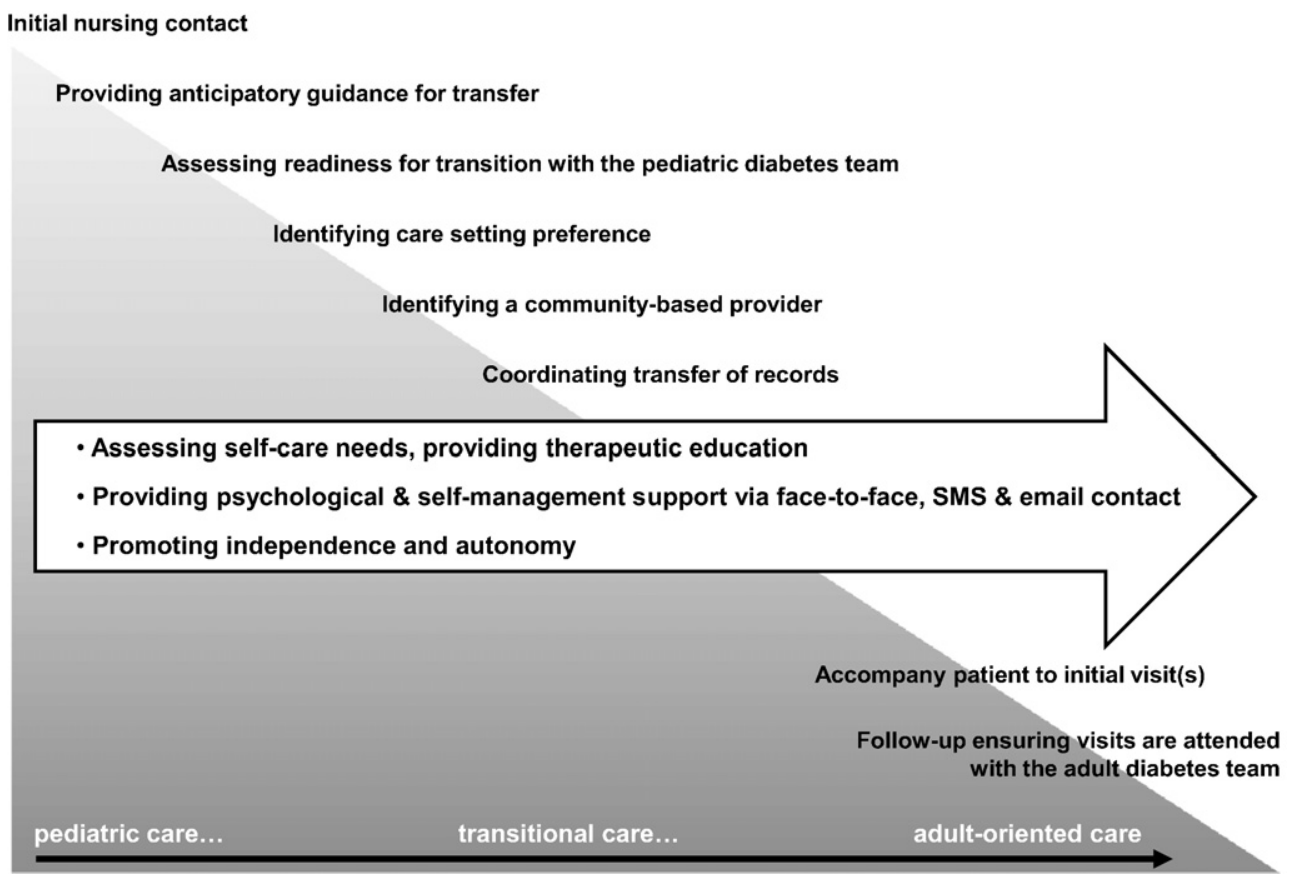

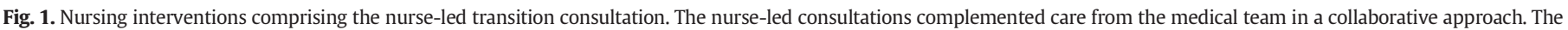

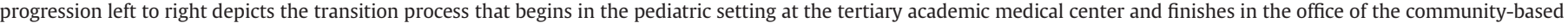
provider of adult-oriented care. The arrow indicates transversal elements through the process.

\section{Instruments}

The Self Care Inventory is a validated 15-item self-report instrument using a 5-point Likert-type scale $(1=$ 'never do it' to $5=$ 'always do this as recommended, without fail') to assess key aspects of managing T1DM such as glucose monitoring, medication administration, managing low glucose levels, diet, exercise and routine preventative care (i.e. keeping appointments with providers) (Lewin et al., 2009). Higher scores indicate higher levels of self-care. The revised scale (SCI-R) has demonstrated good internal consistency ( $\alpha=0.87$ ), fair construct validity (self-efficacy: $r=0.47$; HbA1c: $r=-0.37)$ and scores are responsive to diabetes education interventions (Weinger, Butler, Welch, \& La Greca, 2005). SCIscores can be converted to a $0-100$ scale according to the formula ([mean row score-minimum] $\times 100$ ) / (maximum-minimum) for ease of interpretation and ease of comparison (Weinger et al., 2005). For this study, one question related to wearing a medic-alert bracelet was omitted as it was not culturally relevant. Thus, scores were based on 14 items.

To assess the therapeutic relationship, patients completed the Caring Nurse-Patient Interaction Short Scale (CNPI-23) (Cossette, Cote, Pepin, Ricard, \& D'Aoust, 2006; Cossette, Pepin, Cote, \& de Courval, 2008). This 23-item instrument evaluates patient perceived importance and observed frequency of nurses' caring attitudes and behaviors during consultations as well as patient satisfaction with the care relationship (Cossette et al., 2008). The instrument has been used to evaluate elements of caring in relation to nursing practice using a 5-point Likerttype scale assessing importance (not at all, a little, moderately, a lot, extremely), frequency (almost never, sometimes, often, very often, almost always), and satisfaction (very unsatisfied, unsatisfied, no opinion, satisfied, very satisfied). The instrument comprises four caring domains (Fig. 2): clinical care ( 9 items, $\alpha=0.80-0.94$ ), relational care ( 7 items, $\alpha=0.90-0.92$ ), humanistic care (4 items, $\alpha=0.63-0.74$ ), and comforting care ( 3 items, $\alpha=0.90-0.92$ ) (Cossette et al., 2006).

\section{Analysis}

Results are reported using descriptive statistics. Point-of care HbA1c levels were compared to target levels identified by the ADA (American
Diabetes, 2016) and ISPAD (Rewers et al., 2014) ( $\leq 7.5 \%)$ as well as the United Kingdom National Institute for Health and Care Excellence (NICE) ( $\leq 6.5 \%)$ (Beckles et al., 2016). The cutoff for poor glycemic control $(\geq 9.5 \%)$ was derived from the SEARCH for diabetes in Youth Study (SEARCH) (Petitti et al., 2009). As an exploratory step, Pearson product moment coefficients of correlation or Spearman's rank-order correlations (as appropriate) were performed to identify relationships between self-care and sex, age, age at transition, and duration of transition/disease. Associations between patient ratings of importance and the frequency of the observed caring attitudes/behaviors were evaluated to assess the concordance between observed aspects of nursing consultations and patient priorities. Analyses were performed using STATA13 (StatCorp LP, College Station, TX). $p$ values $<0.05$ were considered statistically significant.

\section{Results}

Of 58 potential patients, 20 (34\%) agreed to participate in the study to evaluate the pilot nurse-led consultations. Approximately a third $(7 / 20,35 \%)$ responded using the web-based questionnaire while the others returned the paper format. Characteristics of the participants are detailed in Table 1. Overall, female patients outnumbered their male counterparts by $2: 1$ and participants ranged in age from 16 to nearly 24 years-old. Patients also varied widely in terms of their duration of living with T1DM (range: $1.9-17.4$ years, median: 7.3 years) and 15/20 (75\%) were self-administering insulin while the remainder were on pump therapy. The median age at transition was 17.7 years and patients had an extended transition period spanning approximately three years.

\section{Glycated Hemoglobin (HbA1c)}

In total, 15/20 (75\%) consented and $14 \mathrm{HbA} 1 \mathrm{c}$ measures were obtained. Values ranged from 5.8-14.3\% (median $8.9 \%$, mean $9.4 \%$ ). When considering recommended target $\mathrm{HbA1c}$ levels for young adults with T1DM, 3/14 (21\%) achieved the ADA/ISPAD target ( $\leq 7.5 \%)$ (American Diabetes, 2016; Rewers et al., 2014) while only 1/14 (7\%) 


\begin{tabular}{|c|c|}
\hline $\begin{array}{l}\text { Clinical care } \\
\text { 1. Knew how to give the treatments } \\
\text { 2. Knew how to operate specialized } \\
\text { 2. intravenous injections) } \\
\text { equipment (e.g., pumps, monitors) } \\
\text { 3. Checked if my medications soothed my } \\
\text { symptoms. } \\
\text { 4. } \begin{array}{l}\text { Gave me indications and means to } \\
\text { treat or prevent certain side effects of }\end{array} \\
\text { my medications or treatments. } \\
\text { 5. Knew what to do in situations where } \\
\text { one must act quickly. } \\
\text { 6. Helped me with the care I cannot } \\
\text { 7. Showed ability and skill in their way of } \\
\text { administer myself. } \\
\text { 8. Closely monitored my health condition. } \\
\text { 9. Provided me with the opportunity to } \\
\text { practice self-administered care. }\end{array}$ & $\begin{array}{l}\text { Relational care } \\
\text { 1. Helped me to look for a certain } \\
\text { equilibrium/balance in my life } \\
\text { 2. Helped me to explore what is important } \\
\text { in my life. } \\
\text { 3. Helped me to clarify which things I } \\
\text { would like significant persons to bring } \\
\text { me }\end{array}$ \\
\hline $\begin{array}{l}\text { Humanistic care } \\
\text { 1. Considered me as a complete } \\
\text { individual, showed that they were } \\
\text { interested in more than my health } \\
\text { problem. } \\
\text { 2. Encouraged me to be hopeful, when it } \\
\text { was appropriate. } \\
\text { 3. Emphasized my efforts. } \\
\text { 4. Did not have an attitude of disapproval. }\end{array}$ & $\begin{array}{l}\text { Comforting care } \\
\text { 1. Respected my privacy. } \\
\text { 2. Took my basic needs into account } \\
\text { (e.g., sleeping, hygiene, etc.) } \\
\text { 3. Did treatments or gave medications at } \\
\text { the scheduled time. }\end{array}$ \\
\hline
\end{tabular}

Fig. 2. Domains of the Caring Nurse-Patient Interactions Scale (CNPI-23) (Cossette et al., 2006; Cossette et al., 2008).

met the criteria set forth in NICE guidelines (i.e. $\leq 6.5 \%$ ) (Beckles et al., 2016). Using the SEARCH cutoff of $\geq 9.5 \%$ (Petitti et al., 2009), 5/15 (36\%) exhibited poor glycemic control.

\section{Self-care}

Twenty patients completed the Revised Self-Care Inventory (SCI-R). On the 15-itme SCI-R, the maximum score is 100 with higher scores indicating better adherence to recommended T1DM self-care. Among patients seen in the structured transition program, scores ranged from 45 to 84 (mean: $65 \pm 12$, median: 68 ). Median ratings were lowest for following dietary recommendations and regular blood glucose monitoring (both $3.0=$ 'sometimes') while highest ratings (between 'regularly' and 'always') were observed for administering insulin and managing hypoglycemia (4.7 and 4.5 respectively). Results for each self-care domain are shown in Fig. 3. No significant associations were identified between self-care and either sex, age, age at transition, or duration of transition/

Table 1

Characteristics of patients $(\mathrm{n}=20)$ receiving nurse-led transition consultations for type 1 diabetes (T1DM).

\begin{tabular}{ll}
\hline Clinical characteristic & Median (range) \\
\hline Age (years) & $21.1(16.2-23.9)$ \\
Age at diagnosis (years) & $11(4.2-17.8)$ \\
Duration of T1DM (years) & $7.3(1.9-17.4)$ \\
Age at 1st transition consultation (years) & $17.7(15.3-20.8)$ \\
Transition duration (months) & $35.6(1.6-51.3)$ \\
Time since last nurse consultation (months) & $1.8(0.2-15.5)$ \\
& \\
& Number $(\%)$ \\
\hline Sex & \\
Female & $13(65 \%)$ \\
Male & $7(35 \%)$ \\
Treatment & \\
Insulin injections & $15(75 \%)$ \\
Insulin pump therapy & $5(25 \%)$ \\
Frequency of physician appointments & \\
$>1$ per month & $1(5 \%)$ \\
Monthly & $2(10 \%)$ \\
Every 3-months & $16(80 \%)$ \\
Less frequently than quarterly & $1(5 \%)$ \\
Frequency of nurse-led consultations & \\
$>1$ per month & $2(10 \%)$ \\
Monthly & $2(10 \%)$ \\
Every 3-months & $3(15 \%)$ \\
Less frequently than quarterly & $13(65 \%)$ \\
\hline
\end{tabular}

disease. However, this lack of association should be viewed with caution given the small pilot sample.

\section{Therapeutic Relationship}

All but one patient fully completed the Caring Nurse-Patient Interaction Short Scale. Overall, patients valued caring attitudes and behaviors as evidenced by high ratings of importance ( $3.8 \pm 0.5$ out of 5$)$. They also reported having frequently observed these elements $(3.5 \pm 0.9$ out of 5) as part of the nurse-led transition consultations. Global satisfaction ratings were high $(4.0 \pm 0.5$ out of 5$)$ suggesting patients deemed the consultations acceptable. When examining the different facets of caring (i.e. clinical, relational, humanistic, and comfort), we observed that humanistic and comforting caring (i.e., encouraging and accompanying) attitudes/behavior received the highest ratings for importance. The most frequently observed attitudes/behaviors in consultations were comforting care followed by clinical and humanistic care. Patients gave the highest satisfaction ratings to humanist and comforting care (Fig. 4). These two domains relates to attitudes and behaviors that reflect the nurse respecting privacy while taking into account the internal resources of the patient and to use these for active coping and to find solutions to challenges (i.e., empowerment). Notably, being considered as an individual, beyond being a patient with T1DM, was identified as one of the most important aspects (10/19, 53\% rated 'extremely important', i.e., 5/5) and 13/19 (68\%) reported it was 'almost always' (i.e., 5/5) part of the nurse-led consultation. It is perhaps not surprising that the same number of patients $(n=13)$ were 'very satisfied' (i.e. 5/5) with this aspect of the nurse's attitude and behavior within the transition consultation.

Notably, relational items (e.g. 'Helps me to explore what is important in my life') were rated as the least important and least often observed in the context of the consultations (Fig. 4). In the exploratory analysis, importance and frequency were strongly correlated globally $(r=0.81, p<0.001$ ) as well as across all domains (range: $0.71-0.83$, all $<0.001)$. Moreover, the relative importance of clinical caring was significantly related to ratings of satisfaction $(r=0.80, p<0.001)$. This was not the case for relational caring $(r=0.44$, N.S.). Overall, the more frequently that caring attitudes/behaviors were observed, the greater the rating of satisfaction $(r=0.82, p<0.001)$. The lowest rating of satisfaction was noted for a clinical care domain question (Fig. 2) "Gave indications and means to treat or prevent certain side-effects of medications or treatments" (mean $2.89 \pm 0.94$ ). 


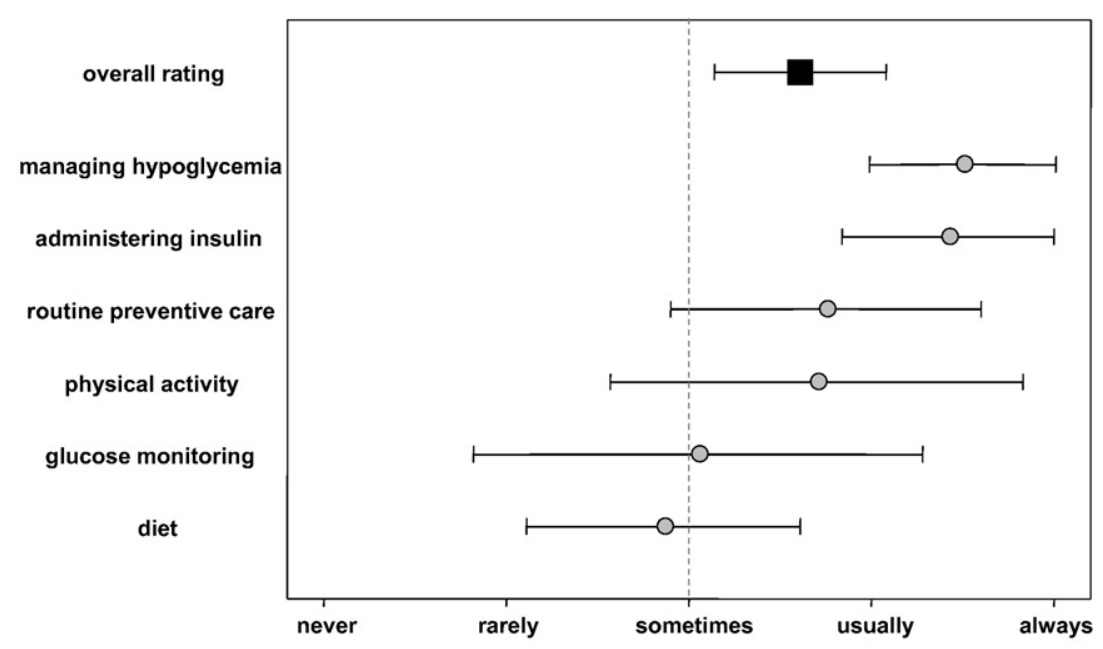

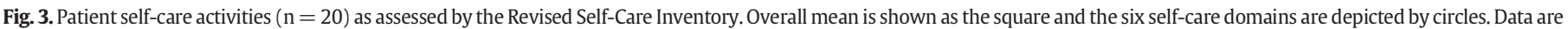
reported as mean \pm standard deviation. The Likert-type frequency rating is shown on the horizontal axis and the middle rating is depicted by the vertical dashed line.

\section{Discussion}

Herein we report data supporting the acceptability of nurse-led transition consultations as part of a structured transitional care program moving young adults with T1DM from a tertiary academic medical center to adult-oriented community-based practices.

The model employed in the present study incorporated some elements of logistical support employed in prior studies while embracing the important role that nursing can play in transitional care beyond an administrative role. The transition nurse's key contribution is in establishing a caring therapeutic relationship as a bridge to adult-oriented community-based practices and providing tailored therapeutic education promoting self-efficacy and supporting self-management. Indeed, recent meta-analyses have demonstrated the efficacy of therapeutic education for enhancing self-care (Reddy, Rilstone, Cooper, \& Oliver, 2016; Tshiananga et al., 2012). Notably, nearly two-thirds of patients met with the nurse less than quarterly. This suggests that the frequency of consultations may not be the factor that matters most. Rather, the knowledge that a support and safety net is there may contribute to patient satisfaction.

Over the past 15 years, a number of studies have examined patient perspectives on the transition process (Betz et al., 2016; Lotstein et al., 2013). Notably, a common theme is dissatisfaction with services
(Busse et al., 2007; Garvey et al., 2012; Kipps et al., 2002). In the present study, the nurse-led transition consultations received high marks for patient satisfaction. Notably, 17/19 (90\%) rated respect for privacy as 'extremely important' and 14/19 (74\%) reported that this was 'almost always' observed in consultations. Patients did not want the nurse to be their counselor (i.e. helping them to find meaning in their life - relational caring). Rather, they preferred an approach of accompanying and encouraging and were highly satisfied with the clinical aspects of caring such as the nurse providing opportunities to learn and practice self-care. This is in line with a prior mixed-methods study of adolescents with chronic conditions underscoring the importance of clinical expertise as a key characteristic of healthcare providers (van Staa, Sattoe, \& Strating, 2015). Interestingly, relational items were rated as the least important. This may reflect the growing independence young adults during transition and serves as the counterpoint to the humanistic aspect of considering the patient as a complete individual and respecting patient autonomy (Table 2 ).

These data provide insight into the nurse profile that is responsive to young adult patient preferences, i.e. individualized care (Hilliard et al., 2014; Price et al., 2011). Specifically, young adults in the present study expressed desire for a clinically competent nurse who respects patient privacy and autonomy in a developmentally appropriate manner and who adopts a holistic approach recognizing them as a whole person -
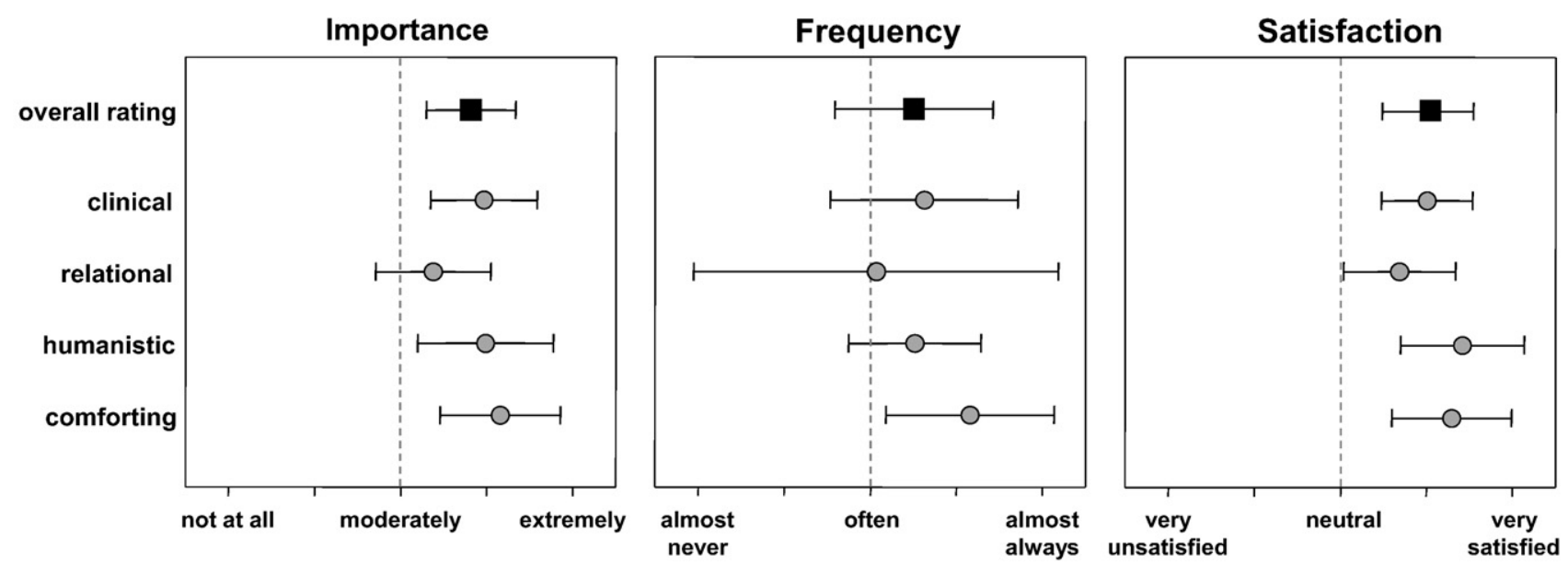

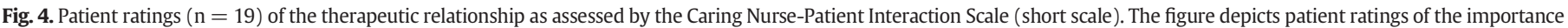

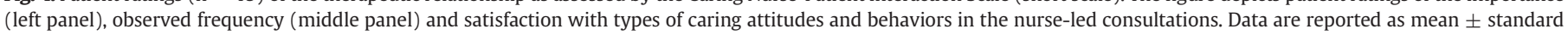
deviation. Respective Likert-type ratings are shown on the horizontal axis and the middle rating is depicted by the vertical dashed line. 
Table 2

Highest rated nursing attitudes and behaviors of caring (CNPI-23) in terms of patients' perceived importance, observed frequency and satisfaction $(\mathrm{n}=19)$.

\begin{tabular}{|c|c|c|c|c|}
\hline Item & Sub-domain & Importance & Frequency & Satisfaction \\
\hline Considers me as a complete individual, interested in more than my health problems & Comforting & $4.3 \pm 1.0$ & $4.2 \pm 1.3$ & $4.6 \pm 0.8$ \\
\hline Respects my privacy & Humanistic & $4.4 \pm 0.7$ & $4.6 \pm 0.8$ & - \\
\hline Encourages me to be hopeful & Humanistic & $4.3 \pm 1.0$ & - & - \\
\hline Takes my basic needs into account & Comforting & - & $4.2 \pm 1.3$ & - \\
\hline Provides me with the opportunity to practice self-administered care & Humanistic & - & - & $4.6 \pm 0.7$ \\
\hline Does not have a disapproving attitude & Humanistic & - & - & $4.6 \pm 0.7$ \\
\hline
\end{tabular}

and not solely as a patient with T1DM. Thus, it seems that recognizing the whole person is an important aspect for helping to empower and activate patients for diabetes self-management.

Difficulty in establishing a relationship with adult-oriented community-based professionals is one of the factors underlying young adults discontinuing care and being lost to follow-up (Nguyen et al., 2016; Price et al., 2011; Rutishauser, Sawyer, \& Ambresin, 2014). Several studies, including systematic reviews of the literature, have found that the successful transition is strongly associated with the quality of the care relationship (Findley, Cha, Wong, \& Faulkner, 2015; Monaghan, Hilliard, Sweenie, \& Riekert, 2013; Ritholz et al., 2014). While the nurse-led transition consultation were acceptable and received high satisfaction ratings, patients were not entirely satisfied with knowing how to anticipate/identify side effects of their treatment as a means to treat/prevent such potential undesired effects (Fig. 2). This may reflect the complexity of diabetes management and the particular challenges of insulin therapy. This is interesting in light of the results from the Self-Care Inventory (SCI-R) which indicated relatively high scores for administering insulin ( $4.4 \pm 0.6$ out of 5 ) and managing hypoglycemia $(4.5 \pm 0.5$ out of 5$)$ (Fig. 3). This could indicate that despite following recommendations for self-care that patients desired more information and training on treating and preventing side effects of their insulin therapy. As glycemic control is noted to decrease with passage to adult-oriented services (Petitti et al., 2009), it would be interesting to see of in a longitudinal manner if the transition nurse's therapeutic education interventions could demonstrate increased SCI-R scores - yet sensitivity may be limited by a ceiling effect.

The median HbA1c value in our study was $8.9 \%$, similar to the data from the 2009 SEARCH study ( $8.2 \pm 1.6)$ that included nearly 4000 children and adolescents with T1DM. Our data suggest that reaching target HbA1c levels remains elusive in this patient population. This begs the question regarding realistic goals for HbA1c during transition. It may not be realistic to expect improvements in HbA1c. Rather, perhaps the absence of deteriorating scores may be a more feasible objective.

As this study was a cross-sectional study of a pilot project, the number of patients is relatively small and results should be interpreted with caution. The $34 \%$ response rate to the survey is another potential source of selection bias. Further, there is also the possibility of conditional sampling bias wherein patients who were satisfied with the program accepted participation. Additionally, it should be noted that as one question was excluded from the adherence instrument, total adherence scores were not able to be calculated. In light of these facets, we emphasize that caution should be taken when generalizing these findings.

Transition is a process rather than a singular event and represents a planned, purposeful transfer of care from pediatric setting to adult-oriented care (American Diabetes, 2016). The nurse-led consultation described herein is a multi-faceted complex intervention integrated into a structured transition program. These consultations were well-accepted and responsive to patient needs and desires. This is one of the few studies that has dissected the relative contribution of specific elements of a structured transition. Further, these data highlight the important role that nursing can have in responding to the transitional care needs of young adults with T1DM as them move into adult-oriented community-based practices.

In terms of practice implications, these data support the notion that nurse-led consultations incorporating therapeutic education for self- management can have an important and complementary role to the medical team during transition. There is yet consensus on the most appropriate/optimal outcomes that are key for evaluating transitional care models. The present study was useful for examining nursing-sensitive aspects. However, questions remain as to how we should best evaluate and measure continuity of care, long-term health (and wellbeing) outcomes as well as the financial impact of such programs. While the clinical importance appears evident, more work is needed to delineate best practices for evaluating and comparing structured transitional care programs.

\section{Acknowledgements}

We thank the patients and their families for their generous participation. We wish to acknowledge the collaboration of the Programme Cantonal Diabète (Vaud). We are grateful to Prof. Annette La Greca for use of the SCI-R and Prof. Sylvie Cossette for use of the CNPI-23. This research was carried out as part of the Master of nursing science joint program between the University of Lausanne and the University of Applied Sciences Western Switzerland (S.Z., M-E.V.). This project did not receive any specific grant from funding agencies in the public, commercial, or not-for-profit sectors.

\section{References}

American Diabetes, A. (2016). 11. Children and adolescents. Diabetes Care, 39(Suppl. 1) S86-93. https://doi.org/10.2337/dc16-S014.

Beckles, Z. L., Edge, J. A., Mugglestone, M. A., Murphy, M. S., Wales, J. K., \& Guideline Development, G. (2016). Diagnosis and management of diabetes in children and young people: Summary of updated NICE guidance. BMJ, 352, i139. https://doi.org/ 10.1136/bmj.i139.

Betz, C. L. (2017). SPN position statement: Transition of pediatric patients into adult care Journal of Pediatric Nursing, 35, 160-164. https://doi.org/10.1016/j.pedn.2017.05.003.

Betz, C. L., Lobo, M. L., Nehring, W. M., \& Bui, K. (2013). Voices not heard: A systematic review of adolescents' and emerging adults' perspectives of health care transition. Nursing Outlook, 61(5), 311-336. https://doi.org/10.1016/j.outlook.2013.01.008.

Betz, C. L., O'Kane, L. S., Nehring, W. M., \& Lobo, M. L. (2016). Systematic review: Health care transition practice service models. Nursing Outlook, 64(3), 229-243. https://doi. org/10.1016/j.outlook.2015.12.011.

Busse, F. P. Hiermann, P., Galler, A., Stumvoll, M., Wiessner, T., Kiess, W., \& Kapellen, T. M. (2007). Evaluation of patients' opinion and metabolic control after transfer of young adults with type 1 diabetes from a pediatric diabetes clinic to adult care. Hormone Research, 67(3), 132-138. https://doi.org/10.1159/000096583.

Cadario, F., Prodam, F., Bellone, S., Trada, M., Binotti, M., Trada, M., ... Aimaretti, G. (2009) Transition process of patients with type 1 diabetes (T1DM) from paediatric to the adult health care service: A hospital-based approach. Clinical Endocrinology, 71(3), 346-350. https://doi.org/10.1111/j.1365-2265.2008.03467.x

Campbell, F., Biggs, K., Aldiss, S. K., O'Neill, P. M., Clowes, M., McDonagh, J., ... Gibson, F. (2016). Transition of care for adolescents from paediatric services to adult health services. Cochrane Database of Systematic Reviews, 4, CD009794. https://doi.org/10.1002/ 14651858.CD009794.pub2.

Cossette, S., Cote, J. K., Pepin, J., Ricard, N., \& D'Aoust, L. X. (2006). A dimensional structure of nurse-patient interactions from a caring perspective: Refinement of the Caring Nurse-Patient Interaction Scale (CNPI-Short Scale). Journal of Advanced Nursing 55(2), 198-214. https://doi.org/10.1111/j.1365-2648.2006.03895.x.

Cossette, S., Pepin, J., Cote, J. K., \& de Courval, F. P. (2008). The multidimensionality of caring: A confirmatory factor analysis of the Caring Nurse-Patient Interaction Short Scale. Journal of Advanced Nursing, 61(6), 699-710. https://doi.org/10.1111/j.13652648.2007.04566.x.

Cox, C. L. (1982). An interaction model of client health behavior: Theoretical prescription for nursing. ANS. Advances in Nursing Science, 5(1), 41-56.

Dunger, D. B. (2017). Banting Memorial Lecture 2016 Reducing lifetime risk of complications in adolescents with Type 1 diabetes. Diabetic Medicine, 34(4), 460-466. https:// doi.org/10.1111/dme.13299. 
Findley, M. K., Cha, E., Wong, E., \& Faulkner, M. S. (2015). A systematic review of transitional care for emerging adults with diabetes. Journal of Pediatric Nursing, 30(5), e47-62. https://doi.org/10.1016/j.pedn.2015.05.019.

Funnell, M. M., \& Anderson, R. M. (2000). MSJAMA: The problem with compliance in diabetes. JAMA, 284(13), 1709.

Garvey, K. C., Markowitz, J. T., \& Laffel, L. M. (2012). Transition to adult care for youth with type 1 diabetes. Current Diabetes Reports, 12(5), 533-541. https://doi.org/10.1007/ s11892-012-0311-6.

Hauschild, M., Elowe-Gruau, E., Dwyer, A., Aquarone, M. P., Unal, S., Jornayvaz, F. R., .. Schwitzgebel, V. M. (2015). Transition in diabetology. Revue Médicale Suisse, 11(462), 450-452 (454-455).

Hilliard, M. E., Perlus, J. G., Clark, L. M., Haynie, D. L., Plotnick, L. P., Guttmann-Bauman, I., \& Iannotti, R. J. (2014). Perspectives from before and after the pediatric to adult care transition: A mixed-methods study in type 1 diabetes. Diabetes Care, 37(2), 346-354. https://doi.org/10.2337/dc13-1346.

Holmes-Walker, D. J., Llewellyn, A. C., \& Farrell, K. (2007). A transition care programme which improves diabetes control and reduces hospital admission rates in young adults with Type 1 diabetes aged 15-25 years. Diabetic Medicine, 24(7), 764-769. https://doi.org/10.1111/j.1464-5491.2007.02152.x.

Kipps, S., Bahu, T., Ong, K., Ackland, F. M., Brown, R. S., Fox, C. T., ... Dunger, D. B. (2002). Current methods of transfer of young people with Type 1 diabetes to adult services. Diabetic Medicine, 19(8), 649-654.

Klostermann, B. K., Slap, G. B., Nebrig, D. M., Tivorsak, T. L., \& Britto, M. T. (2005). Earning trust and losing it: Adolescents' views on trusting physicians. The Journal of Family Practice, 54(8), 679-687.

Lachin, J. M., Orchard, T. J., Nathan, D. M., \& DCCT/EDIC Research Group (2014). Update on cardiovascular outcomes at 30 years of the diabetes control and complications trial/ epidemiology of diabetes interventions and complications study. Diabetes Care, 37(1), 39-43. https://doi.org/10.2337/dc13-2116.

Lewin, A. B., LaGreca, A. M., Geffken, G. R., Williams, L. B., Duke, D. C., Storch, E. A., \& Silverstein, J. H. (2009). Validity and reliability of an adolescent and parent rating scale of type 1 diabetes adherence behaviors: The Self-Care Inventory (SCI). Journal of Pediatric Psychology, 34(9), 999-1007. https://doi.org/10.1093/jpepsy/jsp032.

Lotstein, D. S., Seid, M., Klingensmith, G., Case, D., Lawrence, J. M., Pihoker, C., ... SEARCH for Diabetes in Youth Study Group (2013). Transition from pediatric to adult care for youth diagnosed with type 1 diabetes in adolescence. Pediatrics, 131(4), e1062-1070. https://doi.org/10.1542/peds.2012-1450.

Lyons, S. K., Becker, D. J., \& Helgeson, V. S. (2014). Transfer from pediatric to adult health care: Effects on diabetes outcomes. Pediatric Diabetes, 15(1), 10-17. https://doi.org/ 10.1111/pedi.12106.

Maahs, D. M., Hermann, J. M., DuBose, S. N., Miller, K. M., Heidtmann, B., DiMeglio, L. A., ... Network, T. D. E. C. (2014). Contrasting the clinical care and outcomes of 2,622 children with type 1 diabetes less than 6 years of age in the United States T1D Exchange and German/Austrian DPV registries. Diabetologia, 57(8), 1578-1585. https://doi.org/ 10.1007/s00125-014-3272-2.

Maahs, D. M., West, N. A., Lawrence, J. M., \& Mayer-Davis, E. J. (2010). Epidemiology of type 1 diabetes. Endocrinology and Metabolism Clinics of North America, 39(3), 481-497. https://doi.org/10.1016/j.ecl.2010.05.011.

Mayer-Davis, E. J., Lawrence, J. M., Dabelea, D., Divers, J., Isom, S., Dolan, L., ... SEARCH for Diabetes in Youth Study (2017). Incidence trends of type 1 and type 2 diabetes among youths, 2002-2012. The New England Journal of Medicine, 376(15) 1419-1429. https://doi.org/10.1056/NEJMoa1610187.

Miller, K. M., Foster, N. C., Beck, R. W., Bergenstal, R. M., DuBose, S. N., DiMeglio, L. A., .. Network, T. D. E. C. (2015). Current state of type 1 diabetes treatment in the U.S.: Updated data from the T1D Exchange clinic registry. Diabetes Care, 38(6), 971-978. https://doi.org/10.2337/dc15-0078.
Monaghan, M. Hilliard, M., Sweenie, R \& Riekert, K. (2013). Transition readiness in adolescents and emerging adults with diabetes: The role of patient-provider communication. Current Diabetes Reports, 13(6), 900-908. https://doi.org/10.1007/s11892013-0420-X.

Nakhla, M., Daneman, D., To, T., Paradis, G., \& Guttmann, A. (2009). Transition to adult care for youths with diabetes mellitus: Findings from a Universal Health Care System. Pediatrics, 124(6), e1134-1141. https://doi.org/10.1542/peds.2009-0041.

Nguyen, T. Henderson, D. Stewart, D. Hlyva, O Punthakee Z \& Gorter J. W. (2016). You never transition alone! Exploring the experiences of youth with chronic health conditions, parents and healthcare providers on self-management. Child: Care, Health and Development, 42(4), 464-472. https://doi.org/10.1111/cch.12334.

Peng, H., \& Hagopian, W. (2006). Environmental factors in the development of Type 1 diabetes. Reviews in Endocrine E Metabolic Disorders, 7(3), 149-162. https://doi.org/10. 1007/s11154-006-9024-y.

Petitti, D. B., Klingensmith, G. J., Bell, R. A., Andrews, J. S., Dabelea, D., Imperatore, G, SEARCH for Diabetes in Youth Study Group (2009). Glycemic control in youth with diabetes: The SEARCH for diabetes in Youth Study. The Journal of Pediatrics, 155(5), 668-672. https://doi.org/10.1016/j.jpeds.2009.05.025 (e661-663).

Price, C. S., Corbett, S., Lewis-Barned, N., Morgan, J., Oliver, L. E., \& Dovey-Pearce, G. (2011). Implementing a transition pathway in diabetes: A qualitative study of the experiences and suggestions of young people with diabetes. Child: Care, Health and Development, 37(6), 852-860. https://doi.org/10.1111/j.1365-2214. 2011.01241.x.

Rawshani, A., Rawshani, A., Franzen, S., Eliasson, B., Svensson, A. M., Miftaraj, M., ... Gudbjornsdottir, S. (2017). Mortality and cardiovascular disease in type 1 and type 2 diabetes. The New England Journal of Medicine, 376(15), 1407-1418. https://doi. org/10.1056/NEJMoa1608664.

Reddy, M., Rilstone, S., Cooper, P., \& Oliver, N. S. (2016). Type 1 diabetes in adults: Supporting self management. BMJ, 352, i998. https://doi.org/10.1136/bmj.i998.

Rewers, M. J., Pillay, K., de Beaufort, C., Craig, M. E., Hanas, R., Acerini, C. L., ... Adolescent, D. (2014). ISPAD Clinical Practice Consensus Guidelines 2014. Assessment and monitoring of glycemic control in children and adolescents with diabetes. Pediatric Diabetes, 15(Suppl. 20), 102-114. https://doi.org/10.1111/pedi.12190.

Ritholz, M. D., Wolpert, H., Beste, M., Atakov-Castillo, A., Luff, D., \& Garvey, K. C. (2014). Patient-provider relationships across the transition from pediatric to adult diabetes care: A qualitative study. The Diabetes Educator, 40(1), 40-47. https://doi.org/10. $1177 / 0145721713513177$.

Rutishauser, C., Sawyer, S. M., \& Ambresin, A. E. (2014). Transition of young people with chronic conditions: A cross-sectional study of patient perceptions before and after transfer from pediatric to adult health care. European Journal of Pediatrics, 173(8), 1067-1074. https://doi.org/10.1007/s00431-014-2291-9.

Tshiananga, J. K., Kocher, S., Weber, C., Erny-Albrecht, K., Berndt, K., \& Neeser, K. (2012). The effect of nurse-led diabetes self-management education on glycosylated hemoglobin and cardiovascular risk factors: A meta-analysis. The Diabetes Educator, 38(1), 108-123. https://doi.org/10.1177/0145721711423978.

van Staa, A., Sattoe, J. N., \& Strating, M. M. (2015). Experiences with and outcomes of two interventions to maximize engagement of chronically ill adolescents during hospital consultations: A mixed methods study. Journal of Pediatric Nursing, 30(5), 757-775. https://doi.org/10.1016/j.pedn.2015.05.028.

Van Walleghem, N., Macdonald, C. A. \& Dean, H. J. (2008). Evaluation of a systems navigator model for transition from pediatric to adult care for young adults with type 1 diabetes. Diabetes Care, 31(8), 1529-1530. https://doi.org/10.2337/ dc07-2247.

Weinger, K., Butler, H. A., Welch, G. W., \& La Greca, A. M. (2005). Measuring diabetes selfcare: A psychometric analysis of the Self-Care Inventory-Revised with adults. Diabetes Care, 28(6), 1346-1352. 